\title{
SOBRE A SUBVERSÃO APLICADA AO PROCESSO EDUCACIONAL
}

\author{
Ana Carolina de Lima Feorenzano ${ }^{1}$ \\ Bianca de Lima Santos Françon ${ }^{2}$ \\ Daniela da Silva Timóteo ${ }^{3}$ \\ Isabella Trento Rufo ${ }^{4}$ \\ Vivianne Augusta Pires Simões ${ }^{5}$
}

FEORENZANO, A. C. de L.; FRANÇON, B. de L. S.; TIMÓTEO, D. da S.; RUFO, I. T.; SIMÕES, V. A. P. Sobre a subversão aplicada ao processo educacional. EDUCERE - Revista da Educação, Umuarama, v. 17, n. 1, p. 33-47, jan./jun. 2017

RESUMO: Há algum tempo tem-se falado de doutrinação nas escolas e universidades, no sentido de rapto moral, cultural, ideológico e político ao invés de uma educação baseada na ética e na verdade. Diante disso, passaram a existir algumas iniciativas públicas contráriasàessaabordagemeducacional, como a organização não governamental "Escola Sem partido" e discussões nas altas esferas da Justiça, como ocorrido no estado de Santa Catarina. Tal doutrinação ocorre por muitos meios e de muitos modos, correspondendo a um projeto sistemático. Tal realidade se mostra racionalizada, abrangendo a escola e ambientes externos ao contexto educacional. A meta é o rapto moral e uma alteração na cosmovisão do sujeito que não mais passa a ser orientado por valores morais, mas por causas de militância política e ideológica.

PALAVRAS-CHAVE: Doutrinação; Educação: Escolas; Humanidade; Política; Subversão.

DOI: https://doi.org/10.25110/educere.v17i1.2017.6281

${ }^{1}$ Acadêmica de Pedagogia pela Unipar - Universidade Paranaense, Rua Vicente Danhoni, 1797.

Cep: 87505512, Umuarama-PR, E-mail: anacarolfiorenzano@hotmail.com

${ }^{2}$ Acadêmica de Pedagogia pela Unipar - Universidade Paranaense, Rua Joana Darc, 4672.

Cep: 87509100, Umuarama-PR, E-mail: biancadelima_sfrancon@hotmail.com

${ }^{3}$ Acadêmica de Pedagogia pela Unipar - Universidade Paranaense, Av. Raimundo José dos Santos, 443, Cep: 87470000, Umuarama-PR.

${ }^{4}$ Acadêmica de Pedagogia pela Unipar - Universidade Paranaense, Rua Mandaguari, 5719.

Cep: 87502110, Umuarama-PR, E-mail: Isabella-trento@hotmail.com

${ }^{5}$ Mestre em educação pela UFU, professora da Unipar - Universidade Paranaense

E-mail: vivianne@prof.unipar.br 


\section{THE SUBVERSION APPLIED TO THE EDUCATIONAL PROCESS}

ABSTRACT: For some time, there has been much talk about indoctrination in schools and universities, in the sense of moral, cultural, ideological and political abduction instead of an education based on ethics and truth. As a result, there have been some public initiatives against to this educational approach, such as the non-governmental organization "School Without a Party" and discussions at the highest levels of Justice, such as in the state of Santa Catarina. Such indoctrination occurs by many means and in many ways, corresponding to a systematic project. This reality is rationalized, covering the school and environments outside the educational context. The goal is moral abduction and a change in the subject's worldview that is no longer oriented by moral values, but by causes of political and ideological militancy.

KEYWORDS: Education; Humanity; Indoctrination; Politics; Schools; Subversion.

\section{ACERCA DE LA SUBVERSIÓN APLICADA AL PROCESO EDUCACIONAL}

RESUMEN: Hace tiempo que se habla de adoctrinamiento en las escuelas y universidades, en el sentido de secuestro moral, cultural, ideológico y político en lugar de una educación basada en la ética y en la verdad. Por lo tanto, llegó a existir algunas iniciativas públicas contrarias a ese abordaje educacional, como la organización no gubernamental "Escuela Sin Partido", y las discusiones en los más altos niveles de la Justicia, como ocurrió en el estado de Santa Catarina. Tal adoctrinamiento ocurre por muchos medios y de muchas formas, lo que corresponde a un proyecto sistemático. Tal realidad se muestra racionalizada, incluyendo la escuela y ambientes externos al contexto educativo. El objetivo es el secuestro moral y cambio en la cosmovisión del sujeto que ya no pasa a ser guiado por valores morales, sino por causas de militancia política e ideológica. PALABRAS CLAVE: Adoctrinamiento; Educación; Escuelas; Humanidad; Política; Subversión. 


\section{INTRODUÇÃO}

Atualmente está em voga utilizar a palavra doutrinação para se referir à uma educação de caráter antirrealista, com o propósito de cooptação cultural, política e ideológica de crianças, adolescentes e universitários em instituições de ensino. Percebe-se, então, a formação de militantes, que sendo movidos por paixões e não razão impossibilita a discordância e dissidência conscientes. Contudo, há um pequeno erro de emprego do termo "doutrinação". Sua correção é necessária para prosseguir o texto. O significado utilizado não deve ser excluído, apenas é impreciso, por ser uma expressão parcial. No presente sentido, ele é tratado como sinônimo de outra palavra, ainda mais importante e que é a causa real: subversão, que ao lado de doutrinação exprime a realidade em totalidade.

Isto significa também que há uma troca indevida do fenômeno de origem pelo de efeito. Esse esclarecimento é necessário pelas seguintes razões: 1) é mais uma palavra correlata e alternada, parte do conjunto e não a coisa toda em si; 2) o contexto atual da educação, isto é, como a prática educacional está acontecendo, não mostra haver doutrinação propriamente dita, mas retrocesso intelectual, ou seja, degradação da mente. Pior ainda é observar que não está acontecendo educação alguma, já que o professor mal consegue ensinar, por indisciplina desinteresse e bagunça por parte dos alunos. 3) "doutrinação" é um termo aplicado posteriormente, daí seu status de correlativo antes dele vindo algo chamado subversão; 4) Caso não se dá como passo seguinte de subversão, a doutrinação ocorre pela inoculação de pensamentos, preceitos e condutas em pessoas ingênuas, como crianças; manipuláveis, como adolescentes, ou pela coerção, feita geralmente em adultos. Esta última, só pode ser feita se o doutrinador tiver um poder maior, criando um conflito com obediência forçada e certa castração mental da vítima. Como em adultos, seres já conscientes, deve ocorrer de outra forma o processo de "doutrinação", para passar despercebido, com crianças ele pode ocorrer naturalmente, já que elas dependem de figuras de autoridade e são dadas à obediência quase irrestrita.

Este artigo apresenta-se com o intuito de diferir doutrina de subversão, e de alertar acerca dos males que ambas as realidades, praticadas em sala de aula de qualquer nível, podem causar naqueles que o sofrem. 
Também se pretende expor os meios pelos quais doutrinação e subversões são aplicadas.

\section{SUBVERSÃO}

Subversão etimologicamente, desde a Idade Média e Línguas antigas, passa o significado de destruição, ruína, de sistemas, da lei, de algo físico, enfim, assolar no geral, e esse significado perdura até hoje. Como realce disso, é substantivo do verbo subverter, cuja etimologia é subvertere, junção do prefixo sub (que designa "posição inferior") e vertere (virar), indicando virar de cabeça para baixo. Alguns termos usados como sinônimos, na língua inglesa, são undermine (minar, escavar, solapar, corroer, arruinar gradativamente, enfraquecer, debilitar insidiosamente), overthrow (derrota, ruína, destruição, derrubar, virar, tombar, derrotar, alucinar, enlouquecer), raze (arrasar, destruir completamente, extirpar, demolir, ferir ligeiramente, apagar, riscar) eoverturn (transtorno, contrariedade, reviravolta, derrubar, virar, emborcar, aniquilar). Em francês, renverser (atropelar, derrubar, tombar, prostrar, derramar, virar do avesso ou de ponta-cabeça, inverter) e bouleverser (bagunçar, perturbar). Na língua espanhola, sendo subverter, os sinônimos é transtornar e revolver.

O termo doutrina, que gera doutrinação, não é sinônimo de subversão, mas está relacionado a isso. Trata-se realmente de um corpo de conhecimentos, uma cultura intelectual (intelectual para diferir de cultura, termo genérico, de outras coisas, como cultura de costumes, avicultura, etc.), uma visão de mundo, dum ensino, sem necessidade de apelo à etimologia, já que é bem conhecido e quase inconfundível. E alguma certa doutrina aplicada pode gerar uma subversão, por ser uma cultura da meia-verdade ou da mentira agradável, sempre imposta (coerção) ou acatada por ação prática inteligente não imposta (exposição e aceitação passiva, falta de percepção e até por fraqueza, a uma pessoa, um grupo, uma cultura e/ou sociedade rival, que só então ficará submissa a alguma forma de doutrinação, ou seja, assimilação de novos valores, novos preceitos e "saberes", novas condutas, de uma ou mais doutrinas novas, criando um indivíduo totalmente novo, o "novo homem".

Vale destacar, no entanto, em parte como oposição, em parte não, que às vezes esse novo homem surge espontaneamente, com a(s) 
característica(s) necessária(s) à subversão, sem uma ação planejada de interessados para formá-lo. Contudo, mesmo assim será aproveitado pelo grupo de subversivos, já que nada se faz sem indivíduos, muito menos sem interesses particulares, sem agentes de influência e os insatisfeitos com partes da sociedade são as cobaias perfeitas para lutar contra "a sociedade". O principal é que a própria cultura subversiva é resultado de homens mentalmente subvertidos, dados à maldade, do contrário, essa cultura da mentira e do mal não existiria.

Esse novo ser humano terá uma nova visão de mundo, condicionada por alguns fatores prévios. Tal visão poderá levar a ver injustiças e maldades na ordem social vigente e desejar mudá-la, em parte ou totalmente, para só então sentir-se bem consigo mesmo, ao passo que também julga fazer isso por bem aos outros, já que é incapaz de ver-se como ruim e errado. Se condenasse a si mesmo, evidenciaria não estar totalmente subvertido, e haveria ainda alguma consciência de si mesmo.

Ou seja, trata-se de uma cultura subversiva, que faz da anormalidade o normal, da anemia a norma, que facilita a transformação radical e sem resistência de uma pessoa e um ambiente. Tal realidade é proveniente de uma atitude pragmática do início da modernidade, desassociada de parâmetros morais, que visa simplesmente à manutenção do poder: "Porque o tempo retarda todas as coisas e pode tornar o bem em mal e o mal em bem" (MAQUIAVEL, 1998 p. 20). Logo, os valores nos quais se amparava a virtude passam a ser relativizados. Cabe dizer, em adição, que doutrinação ocorre sempre em pessoas vulneráveis: adultos lesionados, congenitamente, ou em vida, acometidos de déficit de crescimento mental, ou crianças e adolescentes até certa idade, naturalmente submissos às autoridades e manipuláveis.

Daí a utilização comum da palavra doutrinação aplicada à educação, não de subversão, contraposta ao ensino e assimilação entre pessoas conscientes, saudáveis, livres, individuais não coletivistas (existem os individualistas manipuláveis dados a algum coletivismo, não necessariamente ruins por si só, depende do caso) e capazes de fazer confrontação dialética baseando-se em Lógica e veracidade. Cabe dizer, ainda, que a doutrinação, se não depende da vulnerabilidade produzida ou já existente no público ou pessoa-alvo, a partir de uma autoridade a se obedecer, só é doutrinação ainda se for algo forçado, coercitivo; se não for, é subversão. 
A doutrinação é um ato de inoculação de doutrina; a subversão é um ato de destruição, que é arrasar uma estrutura - a social ou a cognitiva. Temos, então, a diferença entre uma educação predominante e primeiramente política, baseada em uma cultura distinta, não necessariamente verdadeira, mas sempre ruim (por ser subversiva). Tal realidade se enquadra no que se diga de real (por conveniência de momento), e ainda assim atraente por um dos lados (que a defende, apesar da maldade inerente a ela), e uma voltada à busca da verdade, mesmo que desagradável ao sujeito, dos fundamentos da realidade às coisas periféricas, de foco na humanidade a partir do indivíduo e na consciência, por outro dos lados, de que a politização é apenas consequência inevitável, já que o homem é um ser político por espécie (não há outras criaturas vivas que façam política).

O famoso escritor e professor universitário C.S.Lewis ${ }^{1}$ defendia a educação antiga e contrapunha-se a nova. Segundo Lewis, a nova educação procura vender uma visão de mundo pré-fabricada, uma visão que não deixa o homem alçar voo para a liberdade de expressão, da cosmovisão e do pensamento, antes, quer mantê-los enjaulados nas cadeias da doutrinação ideológica, como se fossem passarinhos domesticados. Eis o que Lewis diz em um trecho do seu livro A Abolição do Homem:

Enquanto a antiga educação promovia uma iniciação, a nova apenas "condiciona". A antiga lidava com os alunos da mesma maneira que pássaros crescidos lidavam com os filhotes quando lhes ensinavam a voar; a nova lida com eles mais como o criador de aves lida com os jovens pássaros - fazendo deles alguma coisa com propósito que os próprios pássaros desconhecem. Em suma, a educação antiga era uma espécie de propagação - homens transmitindo a humanidade para outros homens; a nova é apenas propaganda. (LEWIS, 1943, p. 12)

\section{SUBVERSÃO X DOUTRINAÇÃO}

Como se nota, subversão e doutrinação são termos diferentes, mas partem do mesmo princípio, ocorrendo alternadamente, embora subverter seja passo necessariamente anterior ao ato de doutrinar, para gerar

\footnotetext{
${ }^{1}$ Um escritor irlandês, que se destacou por seus trabalhos sobre literatura medieval, por suas palestras e escritos cristãos, especialmente a série de livros "As Crônicas de Nárnia".
} 
o solo fértil à nova doutrina. Além do mais, a subversão pode ir muito além da simples doutrinação, que, em caso de indivíduos já enfraquecidos, pode ocorrer como caso isolado; a subversão pode ser um projeto de destruição de uma sociedade inteira, que pode levar anos, e engoli-la, enfraquecendo em algum nível mesmo as pessoas saudáveis.

Pode-se levar um indivíduo a adotar um pensamento errado ou levar milhões pela corrupção subversiva de toda a vida social. Isso também pode ser considerado uma revolução, que é o substantivo do verbo revolver. Mas, toda revolução é ruim? Não necessariamente. A revolução é sempre uma ruptura, mas um clima de revolução permanente é ruim, obviamente porque não deixa haver ordem, algo fixo, e a consciência, tanto como o homem animal, necessita de uma ordem, social e interior.

O que define a qualidade de uma revolução é sua mentalidade orientadora. Se for destrutiva, sendo o caso da subversão, em nome de mentiras ou meias-verdades prazerosas, apenas sob pretexto de boas intenções, haverápessoas praticando genocídios alegando ser em nome do bem e julgando-se sem máculas e erros.

É uma “ditadura do bem”, como diz Lewis (1943), quer dizer, do mal confundido com o bem, a qual nunca se satisfaz, pois sempre julga fazer o melhor por aqueles a quem subordinou, quando encontra um erro a ser retificado na ordem social; do bem jamais as pessoas se fartam. Ainda mais quando é para a manutenção do próprio poder. A ânsia de um ditador assim não acaba e tomamos, por exemplo, Adolf $\mathrm{Hitler}^{2}$, que espalhou toda a doutrina nazista por meio da educação, da mídia e dos meios de comunicação social. Nas palavras do próprio Hitler: "Que sorte para os ditadores que os homens não pensem" e; "Toda propaganda tem que ser popular e acomodar-se à compreensão do menos inteligente dentre aqueles que pretende atingir". É fato que quem controla e educação, governa toda uma nação.

A filósofa alemã Hannah Arendt (1906-1970) presenciou o contexto violento da Segunda Guerra Mundial e da propagação de um mal relativizado como um bem. Por ser judia, acompanhou a morte de seus correligionários semitas em campos de concentração e do quanto os homens que executavam extermínios em massa não se sentiam moralmente

${ }^{2}$ Um político alemão que serviu como líder do Partido Nazista, Chanceler do Reich e Führer da Alemanha Nazista de 1934 até 1945. 
responsáveis por seus atos. Apósanos de exílio, passando pela França e depois Estados Unidos, ela se tornou uma famosa conferencista reconhecida mundialmente. Arendt relata o julgamento de Eichmann, nazista que foi julgado em solo hebreu anos mais tarde por ser o responsável por numerosas mortes no holocausto, e nessa obra célebre descreve:

Era assim que as coisas eram essa era a nova lei da terra, baseada nas ordens do Fuhrer; tanto quanto ele podia ver, seus atos eram os de um cidadão respeitador das leis. Ele cumpria com seu dever, como repetiu insistentemente à polícia e à corte; ele não só obedecia a ordens, ele também obedecia à lei (ARENDT, 2014. p. 152).

Logo, a subversão que o regime nazista propagou no século XX foi tamanha que indivíduos aderiam a essa ideologia e por ela cometiam as maiores atrocidades legitimidades e justificadas racionalmente, com base na suposta supremacia de uma raça. Tal manipulação de multidões provoca inversão de valores e decadência ética nas sociedades, que amparadas por uma instituição, nesse caso o Estado, fazem o mal e não se responsabilizam por ele.

A vontade de quem pode um pouco, e pensa pela óptica apenas do poder, é querer poder sempre mais. E tratando-se de péssimos valores morais que permeiam um pensamento formado a partir do estudo da realidade, objetiva, social, histórica, etc.. Isso tudo tendo em vista a formação de uma cultura de subversão, com finalidade primeiramente política. $\mathrm{O}$ subversivo adepto precisará sempre ver algo mau na ordem vigente, ou manter de uma coisa para outra, que justifique sua ação revolucionária, por mais que moral e intelectualmente não seja, a não ser no seu próprio pensamento, à própria imagem e semelhança.

Ainda mais se for por ânsia de criar uma sociedade perfeita - na realidade e naturalmente, o mal sempre existirá, uma vez que a política é a busca pelo poder, que o poder o é como verbo (ação), e que a subversão revolucionária com uma mentalidade má é destrutiva, seu efeito inevitável é a de concentração de poder em quem ou o que agora tem os recursos e meios políticos (dinheiro, a educação, etc.) que outrora eram dispersos pela sociedade democrática e pertencente a todos ou a indivíduos em nível limitado. 
Tratando-se de um projeto de novo homem, e depois, de uma nova sociedade, não se pode fazer nova sociedade sem novos homens que querem atuar pela causa. Então, o ideal é começar com um esquema de pensamento em que os alvos de subversão recebam automaticamente ou apreciem. Esses esquemas sempre partem de homens que já sofrem de alguma lesão moral e cognitiva. Esses dedicados a observar no mundo qualquer coisa que os impedisse de ver o mal e a mentira naquilo que pensavam ser bom e verdadeiro.

Os responsáveis por isso são sempre os intelectuais: gente fora do ambiente acadêmico autorizado ou em academias de orientação afim. Sendo algo baseado numa meia-verdade ou mentira, sua busca inicial é a transformação, e, por isto, é o poder, sendo algo fundamentalmente político. "Eu posso algo sobre você, mesmo alicerçado numa falsidade e no mal". E aplicando à escola, se faz tanto no mundo social, quer dizer, dos relacionamentos, com qualquer finalidade, entre professor e aluno, aluno e aluno, daí por diante, como do mundo intelectual, do estudo, ou seja, o aluno de si para si mesmo. Ele sob a autoridade do professor e recebendo certos ensinos como reais, ratificados pela nota e a propagá-los pelo resto da vida devido ao ambiente e à autoridade. Fora da escola, o falso ensino, se feito corretamente e com eficácia de influência, pode ser reforçado por outras instâncias, como a vida familiar, a imprensa, os amigos, a aplicação da lei, o relacionamento com o atendente da padaria da esquina, entre outras. E não apenas isto: talvez um dos pontos mais importantes, o teórico educacional utilizado pelo professor, que preconiza certa abordagem de ensino, dando como dois exemplos a tecnicista e a socioconstrutivista.

Essa abordagem começa entre professor-aluno, e modelando a mente, pode se proliferar, entre alunos e alunos, e depois entre amigos, entre familiares, em qualquer relacionamento interpessoal. Tudo é uma influência possível, que pode reforçar o indivíduo como ele é ou deturpá-lo, sem que ele perceba e esteja consciente de si, agravando ainda mais sua inconsciência e falta de percepção, o tornando como uma esponja a todo tipo de estímulo.

\section{MEIOS SUBVERSIVOS}

As escolas e as universidades são importantes exatamente por se- 
rem centros de difusão social do ensino e da formação das pessoas, tanto para a vida intelectual livre e fértil fora como para a vida profissional e intelectual limitada ou apenas profissional. Sendo assim, apenas reproduzirão o que aprenderam como reflexo da verdade, e ao se deparar com o erro, seja por alerta alheio ou por consciência própria, podem fugir ou enfrentar a angústia da mudança interior e exterior.

Além de contarem com o auxílio da burocracia, também um elemento importante da prática subversiva, que pode sufocar o cotidiano das pessoas e gerar revolta, e daí ser aproveitada por espertalhões, e se não isto, ser elemento de impedimento propriamente dito, como ocorre em relação ao empresariado brasileiro, que leva meses para fundar uma empresa, o que não ocorre em países economicamente livres, como Chile, Austrália, Suíça, entre outros. O mesmo ocorrendo para a estruturação, letra e aplicação das leis, a estruturação do ensino e da atividade dos professores e outras coisas. Temos, então, outro fator passível de corrupção estrutural e auxílio subversivo: a economia. A burocracia é uma dimensão da vida social humana, de relação do homem com autoridades, tocando em vontades e necessidades individuais. Temos um elemento da humanidade: a autoridade, ligada à noção de hierarquia. É algo que precisa ser subvertido.

Mas, falando de educação, o mais relevante, relacionado ao campo econômico, é como os alunos, em sala, na escola ou na universidade, aprendem sobre economia: o que foi a Revolução Industrial? O que é o capitalismo? O que é o lucro? Como se define o valor de uma mercadoria? Questões do tipo aparecem.

Para a politização do cidadão é necessária colher da história as opiniões de teóricos que interessem ao plano político ou reinterpretar a história. Também se deve divulgar a versão de reinterpretação, relegando a versão real, mais próxima da verdade ou a mais endossada pelos pesquisadores ao esquecimento. Até que à pessoa ludibriada, subvertida, doutrinada, se torne impensável a antiga perspectiva, que se torna nova a quem desperta do sono da consciência. E o intelecto ele não é solitário, age junto aos valores, que são anteriores à consciência.

Crianças nascem atribuindo valores, sem pensá-los com a consciência, animais também, e a consciência, em idade mais avançada, com maior desenvolvimento humano, vem para detectar, identificar, interpre- 
tar, fazer um juízo e atribuir um valor e caráter de verdade ou inverdade, aceitando ou confrontando. Um dos passos para o plano subversivo é a eliminação da consciência. $\mathrm{O}$ objetivo disso é que o homem se torne uma máquina de atribuir valores conscientemente e não consiga mudar de ideia ou ver novas perspectivas. Sendo o cérebro algo que não distingue entre bem e mal, verdade e mentira, existindo apenas constituído por hormônios, neurotransmissores, aparelho sensorial, etc. Assim, único e mero "pensar", pode ser alienado e manipulável, tendo a consciência apenas como uma subordinada a identificar estímulos conforme uma doutrina ou cosmovisão inoculada, recebida, da qual não se persuadiu livre e conscientemente, com base no compromisso com a verdade. Sempre que isso acontece, quando a pessoa não sabe como recebeu algo, e sua mentalidade já está assolada, viverá de autossugestões emocionais, sentimentais, histéricas e estereotipadas da doutrina de que foi vítima. Desse modo, viverá num processo permanente de autoconvencimento psicótico dessa mesma doutrina e justificação retroativa, a fim de tentar dar razão agora à coisa que antes recebeu sem atenção e cuidado intelectual. Isso, quando a pessoa não é um intelectual, orbitando figuras de autoridade, praticando culto à personalidade, etc.

E como julga fazer isso por bem aos outros, pensando no mal como bem e no bem como mal, se tornará insensível aos outros e julgará falar em nome deles, achando-se pura, sem mácula, exceto quando fere ou transgride os ensinos da doutrina de que foi vítima ou do grupo de ação a que pertence. Se contrariada, ao invés de conscientizar-se do erro e retificar-se, imputará mal ao próximo, não a si mesma, o que implica agir de forma degradante e, às vezes, violenta.

Os intelectuais, por outro lado, podem ser pessoas mais frias, e ao invés de histéricos, tendem mais à psicopatia, o que também pode ocorrer com alguns políticos. Então, temos outra dimensão da humanidade: a consciência, que é sempre a percepção não natural, livre e autodirigida de alguma coisa, com que o homem adquire a verdade dessa alguma coisa por meio do estudo e pode se transformar moralmente de forma contínua até o fim da vida em sua relação com as pessoas, o mundo e as coisas.

A educação e as comunicações de massa - dois setores entregues ao império de intelectuais ativistas que um tanto inconscientemente são os mais dóceis colaboradores do Estado 
modernizante - atacam por todos os meios as velhas relações comunitárias fundadas no costume, na religião ou na natureza das coisas, para acelerar sua substituição por relações criadas artificialmente pela administração estatal ou pela dinâmica do mercado. Cultivam, por exemplo, a mentira de que as novas gerações escapam ao controle paterno porque, graças à TV e aos computadores, ficam mais inteligentes a cada dia que passa — uma asserção que é desmentida pelo miserável desempenho cultural dos geniozinhos tão logo chegam à universidade ou lhes damos um livro para ler (CARVALHO, 2012, Pg172)

Falando em hierarquia, e sua consequente ruína, ela pode ocorrer também na relação professor-aluno. Sem aquela burocracia como característica existente. Também pode ocorrer entre aluno e aluno, quando um deles é tornado autoridade por outra autoridade. Ou quando um aluno, como indivíduo, tem autoridade sobre outro indivíduo, também aluno, por ser mais inteligente.

A abordagem socioconstrutivista é a responsável por isso, ao eliminar a ideia de autoridade, e de hierarquia, por conta de dois itens convergentes: 1) baseia-se na interação social; 2) a verdade não é uma construção individual e consciente, mas coletiva. Interação social traz junto muitos indivíduos, que se agregam, com suas vidas, motivações, valores e pensamentos diferentes. Mas, a verdade, intelectualmente falando, de uma doutrina tanto como de outra (que rivalizem), não pode ser construída coletivamente, exceto por afinidades morais, intelectuais, ideológicas e políticas, para um objetivo comum, que é a verdade, ou o projeto político, de modo que a "construção coletiva dos saberes", da pedagogia socioconstrutivista, se dá mais em termos de valores e de "estrutura social", baseando-se inquestionavelmente numa doutrina ou outra, que pode terminar na mobilização social ou no "novo homem".

Sendo assim, o professor não pode julgar que ensinou algo, muito menos algo consciente, verdadeiro, duradouro e legado às próximas gerações, pois ele é apenas um auxiliador, nem pode esperar que o aluno obedeça a comandos ou fique quieto por conta própria, pois, além da instabilidade natural da juventude, ainda mais de adolescentes e crianças, os alvos mais fáceis do estímulo subversivo, já que se interessam mais por suas autoafirmações, não há separação entre indivíduo maior e menor, 
sendo todos uns só, uma coletividade, unidos apenas por "traço comum consensual e político de alto valor social", sem "indivíduos em si mesmos e abnegados", "separados pela consciência humana", ninguém maior que outro, nem um ensinando algo a outro a menos que o outro, conforme suas preferências e sua mentalidade de momento ou já estabelecida, aceite. Eis aí a tão aclamada "igualdade". É boa?Essa coletividade obedece apenas aos comandos e anseios de grupo. Uma pessoa dissidente, então consciente, passa a ser vista com maus olhos.

Já que foi falado de economia, no campo intelectual, há também o campo social, do homem consumidor e produtivo.

Há também a parte religiosa do homem. Talvez a mais importante no processo subversivo. Por ser ela que, sendo consciente, e dependendo da religião em questão, mais fortemente guarda o homem de ser subvertido, total ou parcialmente, tanto no terreno moral como no intelectual. Conta-se também com o reforço de que os mitos foram um dos primeiros fundadores de civilização, unindo pessoas em prol de um ponto e objetivo comuns, e com vista a agradar e querer o favor de deuses. Deuses, obviamente, que surgiram antes do Estado e da atividade política e todas as suas relações aparecerem de forma sistemática, pensada. E se tratando, por exemplo, do deus cristão, como exemplo de mito, que antecede o Estado e a política, não precisa de política (assunto humano), e o exemplo de Cristo leva o homem ao máximo do sacrifício e do foco no indivíduo, na reflexão moral teológica autocrítica e até sacrifical, ele tem uma proteção até boa contra os desmandos da busca pelo poder, sobretudo tendo que sua obediência e amor se devem a algo acima de si, do homem, da matéria, da sociedade e da política, do Estado.

Há um atrito incontornável entre um grupo e outra como consequência disso. Sendo política a busca pelo poder, e o homem cristão um contrário ao poder, e tendo Deus como poder moderador, há um conflito inevitável entre o subversivo e a religiosidade, se não a cristã, qualquer outra baseada na busca do homem na intimidade ao invés de na matéria, no meio ambiente, no Estado, como é o caso da prática ascética de autodisciplina budista, em busca do nirvana - budismo não é considerável uma religião. Há ainda o judaísmo, que, embora seja uma religião da terra, e que espera um messias terreno, até hoje, não é revolucionário e 
expansionista como o Islã. ${ }^{3}$

Daí a necessidade de pensar as religiões separadamente, embora para um projeto revolucionário de busca pelo poder concentrado e máximo, subvertendo a ordem e o homem, qualquer outro projeto revolucionário, mesmo religioso, é um inimigo potencial. E considerando, ainda, que o homem é a única criatura com dogmas, e que a religiosidade desempenha papel importante na interioridade e vida humanas, por seus benefícios - a existência, consciência e adoção de um Absoluto, a busca por um sentido na vida, um esquema de explicações do Universo (início, finalidade do homem, fim da vida universal, etc., coisas em que somente o homem pensa e que deseja) -, a criação de um poder político com seus próprios mitos, ritos, disciplina, figura a ser cultuada e, assim por diante, de poder concentrado e materialista, baseando-se numa mentalidade e cultura, pode funcionar como um simulacro de religião, substituindo a religiosidade tradicional, transcendental e sobrenatural. $\mathrm{O}$ "novo homem", com esse simulacro religioso, de falsa religião, passa a ter um novo deus, nova disciplina e nova reflexão moral autocrítica, e o Estado, com sua ideologia, se tornam anterior ao homem e sua civilidade, ao invés de composto por civis - a autoridade estatal máxima encarna o "espírito de povo" e fala por ele, tornando-se o absoluto da vez. Alguns vão até o sacrifício em prol dessa nova ordem e novo homem.

Outra parte importante do homem é a Língua e a Lógica, expressas por meio da linguagem. A Língua não é parte integrante necessária da consciência, mas a Lógica é por ser relativa ao ato de saber.

\section{CONSIDERAÇÕES FINAIS}

Diante do conteúdo abordado neste artigo, é possível inferir que a doutrinação e a subversão se dão por muitos meios e acontecem com mais frequência do que se imagina. Hodiernamente, ela se encontrada até mesmo amparada e propagada por Estados que assumem condições ideológicas, colocando-as acima do bem comum. A intenção disso é reconstruir as pessoas a partir de um modelo revolucionário e militante.

Com isso, frequentemente, chega-se à barbárie e relativização

${ }^{3}$ Uma religião abraâmica monoteísta articulada pelo Alcorão, um texto considerado pelos seus seguidores como a palavra literal de Deus (Alá). 
moral completa, uma vez que a doutrinação e a subversão levam a pessoa à uma releitura de vida e alteração de padrões de comportamento. Não há mais atos virtuosos ou viciosos, há apenas atos que beneficiam a militância da causa ideológica ou a prejudicam. Tais parâmetros substituem o bem e o mal, uma vez que as convicções políticas partidárias agora assumem o caráter de bondade absoluta e inquestionável.

Portanto, devem ser uma preocupação da educação brasileira e demais países esses riscos de contaminação ideológica nas escolas desde as bases do ensino. As crianças, desde o início de sua formação escolar estão expostas aos subversores mal intencionados. Deve-se priorizar uma educação de qualidade capaz de formar indivíduos autônomos e não alienados incapazes de pensar e agir de maneira independente.

\section{REFERÊNCIAS}

ARENDT, H. Eichmannem Jerusalém: um relato sobre a banalidade do mal. São Paulo: Companhia das Letras, 2014.

CARVALHO, O. de. $\mathbf{O}$ jardim das aflições: de Epicuro à ressurreição de César. Ensaio sobre o materialismo e a religião civil. Rio de Janeiro: Diadorim, 1995.

O imbecil coletivo: atualidades inculturais brasileiras. Rio de Janeiro: Faculdade da Cidade Editora e Academia Brasileira de Filosofia, 1996.

LEWIS, C. S. A abolição do homem. São Paulo: M. Fontes, 1943. MAQUIAVEL, N. O príncipe. São Paulo: Paz e Terra, 1998.

Recebido em: 26/01/2017

Aprovado em: 22/03/2017 